\section{ANDES

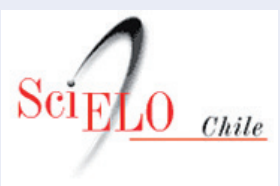

www.scielo.cl

\title{
Challenges of implementing the Paediatric Surviving Sepsis Campaign International Guidelines 2020 in resource-limited settings: A real-world view beyond the academia
}

\section{Desafíos de la utilización de las Guías Pediátricas Internacionales 2020 de la Campaña} Sobreviviendo a la Sepsis en contextos de recursos limitados: Una visión del mundo real más allá de la academia

Gavin Wooldridge ${ }^{\mathrm{a}}$, Nicole O’Brien ${ }^{\mathrm{b}}$, Fiona Muttalib ${ }^{\mathrm{c}}$, Qalab Abbas ${ }^{\mathrm{d}}$, John Adabie Appiah ${ }^{\mathrm{e}}$,Tim Baker, Arun Bansal ${ }^{\mathrm{g}}$, Sangita Basnet ${ }^{\mathrm{h}}$, Santiago Campos-Miño ${ }^{\mathrm{i}}$, Daniela Carla de Souza ${ }^{\mathrm{j}}$, Franco Díaz ${ }^{\mathrm{k}}$, Angela Dramowski ${ }^{1}$, Jaime Fernández-Sarmiento ${ }^{\mathrm{m}}$, Ana Fustiñana ${ }^{\mathrm{n}}$, Gustavo González $^{\circ}$, Roberto Jaborniskyp, Juan Camilo Jaramillo-Bustamante ${ }^{\mathrm{q}}$, Chor Yek Kee Yek Keer, Hans-Joerg Lang ${ }^{\mathrm{s}}$, Vanessa Soares Lanziottit, Guillermo Kohn Loncarica ${ }^{\mathrm{u}}$, Hadi Mohsenibodv, Bunmi Ode ${ }^{\mathrm{w}}$, Srinivas Murthy ${ }^{\mathrm{x}}$, Amelie von Saint Andre-von Arnim ${ }^{y}$, Andreas Hansmann ${ }^{z}$, Sebastián González-Dambrauskas ${ }^{\text {aa }}$

\footnotetext{
aPaediatric Intensive Care, Royal Hospital for Children. Glasgow, United Kingdom

bDepartment of Pediatrics, Division of Critical Care, Nationwide Children's Hospital/The Ohio State University. Columbus, Ohio, USA 'Department of Paediatric Critical Care, BC Children's Hospital. Vancouver, Canada dDepartment of Pediatrics and Child Health, Aga Khan University. Karachi, Pakistan eDepartment of Child Health, Komfo Anokye Teaching Hospital. Kumasi, Ghana

'Muhimbili University of Health and Allied Sciences. Dar es Salaam, Tanzania; and Department of Global Public Health, Karolinska Institutet. Stockholm, Sweden

9Paediatric Emergency and Intensive Care, Advanced Pediatrics Centre, Post Graduate Institute of Medical Education and Research. Chandigarh, India

hPatan Academy of Health Sciences. Kathmandu, Nepal; and Paediatric Critical Care at Southern Illinois University School of Medicine. Springfield, Illinois, USA

Paediatric Intensive Care Unit, Department of Pediatrics, Hospital Metropolitano. Quito, Ecuador

jPediatric Intensive Care Unit, Hospital Universitário da Universidade de São Paulo, Sao Paulo, Brazil; Pediatric Intensive Care Unit Hospital Sírio Libanês, Sao Paulo, Brazil; and Latin America Sepsis Institute (LASI)

kRed Colaborativa Pediátrica de Latinoamérica (LARed Network). Escuela de Postgrado, Universidad Finis Terrae. Santiago de Chile; Unidad de Paciente Crítico Pediátrico, Hospital el Carmen de Maipú. Santiago, Chile

'Department of Paediatrics and Child Health, Stellenbosch University. Cape Town, South Africa

mDepartment of Critical Care Medicine and Pediatrics, Universidad de la Sabana and Fundación Cardioinfantil-Instituto de Cardiología, Graduate School Universidad CES. Bogotá, Colombia

nPaediatric Emergency Department. Hospital Juan P. Garrahan, Universidad de Buenos Aires (UBA), Buenos Aires, Argentina; and Sociedad Latinoamericana de Emergencia Pediatrica (SLEPE)

ñPaediatric Critical Care Unit. Complejo Medico Churruca Visca. Buenos Aires, Argentina; and Paediatric Critical Care Unit, Hospital de Niños Ricardo Gutiérrez. Ciudad Autónoma de Buenos Aires, Argentina
}

Correspondence:

Gavin Wooldridge

gfwooldridge@gmail.com 
-Department of Paediatric, National Northeasthern University, Argentina; Red Colaborativa Pediátrica de Latinoamérica (LARed Network) and Sociedad Latinoamericana de Cuidados Intensivos Pediátricos (SLACIP)

PDepartment of Pediatrics. School of Medicine, Universidad de Antioquia. Medellín, Colombia; Hospital General de Medellín. Medellín, Colombia; and Red Colaborativa Pediátrica de Latinoamérica (LARed Network)

"Sarawak General Hospital. Kuching, Sarawak, Malaysia

rGlobal Child Health Department, University Witten/Herdecke. Witten, North Rhine-Westphalia, Germany; and Paediatric Advisor for NGO ALIMAthe Alliance for International Medical Action

sPaediatric Intensive Care Unit \& Research and Education Division/Maternal and Child Health Postgraduate Program, Federal University of Rio De Janeiro. Rio De Janeiro, Brazil

tPaediatric Emergency Department, Hospital Juan P. Garrahan. Buenos Aires, Argentina; Universidad de Buenos Aires (UBA). Argentina; and Sociedad Latinoamericana de Emergencia Pediatrica (SLEPE)

uPICU, The Hospital for Sick Children. Toronto, Canada; and ERU delegate, Canadian Red Cross, Canada

védiatre Reanimatrice volante. NGO ALIMA-The Alliance for International Medical Action

wDepartment of Paediatric Critical Care, BC Children's Hospital. Vancouver, Canada

×Department of Pediatrics, Division of Paediatric Critical Care, University of Washington, Seattle Children's. Seattle, USA; and Paediatric

Emergency and Critical Care, University of Nairobi. Nairobi, Kenya

yational Pediatric Hospital. Phnom Penh, Cambodia

${ }^{2}$ Cuidados Intensivos Pediátricos Especializados (CIPe), Casa de Galicia. Montevideo, Uruguay; and Red Colaborativa Pediátrica de Latinoamérica (LARed Network)

Received: September 7, 2021; Approved: September 28, 2021

\section{What do we know about the subject matter of this study?}

Pediatric sepsis is a highly prevalent disease and is one of the leading causes of death in children worldwide. The development of the Surviving Sepsis Campaign Guidelines has been an incredible advance for the care of children. However, it does not address issues that are very relevant for resource-limited settings, even in its latest "international" release. Strikingly, middle- and low-income countries are where sepsis has the highest crude cases, incidence, morbidity, and mortality.
What does this study contribute to what is already known?

Despite being a global public health problem, the socio-cultural, political/geographic, and resource context is critical to the approach to sepsis in children. We discuss the particularities and challenges of sepsis care in resource-limited settings, proposing adaptations to current recommendations of Surviving Sepsis Campaign International Guidelines for Pediatric Sepsis and areas for future development and research in resource-limited settings.

\section{Resumen}

Las Guías Internacionales de la Campaña Sobreviviendo a la Sepsis para el Manejo del Shock Séptico y la Disfunción de Órganos Asociada a la Sepsis en Niños, fueron publicadas en 2020 y están destinadas a ser utilizadas en todos los lugares que atienden a niños. Sin embargo, los profesionales que atienden a los niños con sepsis en entornos con recursos limitados se enfrentan a una serie de desafíos y perfiles de enfermedad distintos a los que se encuentran en entornos ricos en recursos. Basándonos en nuestra experiencia colectiva en entornos con recursos limitados, nos propusimos reflexionar sobre las dificultades de aplicar las directrices internacionales. Creemos que hay una necesidad urgente de más evidencia de entornos con recursos limitados en enfoques factibles y eficaces para el tratamiento de la sepsis y el shock séptico que podrían incluirse en las futuras directrices para situaciones y contextos específicos.

\section{Abstract}

The Surviving Sepsis Campaign International Guidelines for the Management of Septic Shock and Sepsis-associated Organ Dysfunction in Children was released in 2020 and is intended for use in all global settings that care for children with sepsis. However, practitioners managing children with sepsis in resource-limited settings (RLS) face several challenges and disease patterns not experienced by those in resource-rich settings. Based upon our collective experience from RLS, we aimed to reflect on the difficulties of implementing the international guidelines. We believe there is an urgent need for more evidence from RLS on feasible, efficacious approaches to the management of sepsis and septic shock that could be included in future context-specific guidelines. 


\section{Introduction}

Sepsis is responsible for $20 \%$ of all global deaths, with over half of all cases occurring in children ${ }^{1}$. The worldwide burden is staggering, yet our understanding of its epidemiology, pathogenesis, and optimal clinical management, remains limited. Evolving definitions and differences in presentation across age groups also complicate the diagnosis of sepsis in children. Although significant progress in child mortality reduction has been made over the last few decades ${ }^{2}$, efforts to reduce sepsis-related mortality face numerous challenges in sepsis in Resource Limited Settings (RLS). A concerted global effort is required to tackle this pressing global health issue collectively.

The prevalence of sepsis in paediatric intensive care unit (PICU) patients varies significantly across regions and with the definition used. For example, one study demonstrated a relatively low prevalence of $6.2 \%$ and $7.7 \%$ in European and North American PICUs, respectively, compared to $15.3 \%$ in Asia, 16.3\% in South America, and 23.1\% in Africa ${ }^{3}$. Thus, the exact prevalence of paediatric sepsis in the community is not known. Extensive work is ongoing to establish programmes to aid sepsis prevention, early recognition and diagnosis, and timely clinical management. However, guidance for ongoing management of these critically ill children, who often present late in their disease course, is lacking. The recent Society of Critical Care Medicine (SCCM)/ European Society of Intensive Care Medicine (ESICM) Surviving Sepsis Campaign International Guidelines for the Management of Septic Shock and Sepsis-associated Organ Dysfunction in Children $(\mathrm{SSG})^{4}$ aimed to provide such guidance through a series of evidence-based recommendation statements. These statements are intended to apply to all patients worldwide with severe sepsis from 37 weeks gestational age at birth to 18 years of age, excluding certain management considerations for neonatal sepsis. In many RLS centres, often with low numbers of staff and minimal critical care training, clear and attainable recommendations could prove lifesaving. However, there is limited evidence specific to RLS available to inform the care of a critically ill child with sepsis. Furthermore, the difficulties that exist in healthcare access and delivery of care, disease pattern, and availability of resources all impact the ability of the provider to implement the guidelines in RLS. Based upon our collective clinical experience, we have reflected on the challenges of implementing these international guidelines when treating critically ill children with sepsis in RLS and highlighted areas for future context-specific research.
What challenges are there when applying the SSG to a critically ill child in a RLS?

Practitioners caring for children with sepsis in RLS encounter various obstacles distinct from those working in resource-rich settings that may ultimately impact the delivery of care and outcome. Several of these are not addressed in the guidelines, including 1) patient factors: the presence of distinct disease pathophysiology and chronic comorbidities (HIV, malnutrition, anaemia, sickle cell disease), 2) pre-hospital factors: delay in illness recognition, absence of emergency transport services and limited pre-referral management options, 3) hospital factors: insufficient staffing and specialty services, lack of equipment, monitoring, medications (including interventions such as transfusion and oxygen and diagnostic tests and weak triage and referral pathways) (figure 1). The profound inequities that exist in healthcare access, availability of resources, delivery of care, and limited evidence base mean many of the current SSG recommendations may not apply to or be feasible in RLS (table 1).

\section{Healthcare access and delivery of care}

The burden of paediatric sepsis, and by extension septic shock and organ dysfunction, is spread across all health facilities, including community, district referral, and tertiary hospitals, both private and public, in RLS. However, unlike in resource-rich settings, most children with sepsis and septic shock will not be cared for in an intensive care unit, nor by health care professionals with formal paediatric or critical care training. Thus, the care and outcome of a critically ill child with sepsis in RLS can solely be dependent upon the patient's geographical location and socioeconomic status. In addition, presentation to a health care facility is often delayed due to various factors, including distance and transport costs ${ }^{5}$, reinforcing the need for clear guidance on managing children with sepsis and septic shock tailored to levels of care.

Regardless of the level of care centre in RLS, deficiencies in trained staff ${ }^{6}$ contribute to a high patient to nurse ratio. As a result, parents or guardians may be partially responsible for monitoring, documentation, and care of their child. Therefore, critically ill children in RLS receive less intensive nursing care than their equivalents elsewhere, potentially adversely affecting patient outcomes. One study in Nepal reported that medical doctors and nurses were present in only $18 \%$ and $41 \%$ of surveyed primary healthcare centres, respectively ${ }^{7}$. Even if resources are available, patient reassessment rate and documentation of vital signs can be poor due to the high volume of patients and limited staff numbers ${ }^{8}$. A survey of 21 RLS hospitals demonstrated that $30 \%$ of inpatients were not moni- 


\section{PAEDIATRIC SEPSIS JOURNEY IN RESOURCE LIMITED SETTINGS}

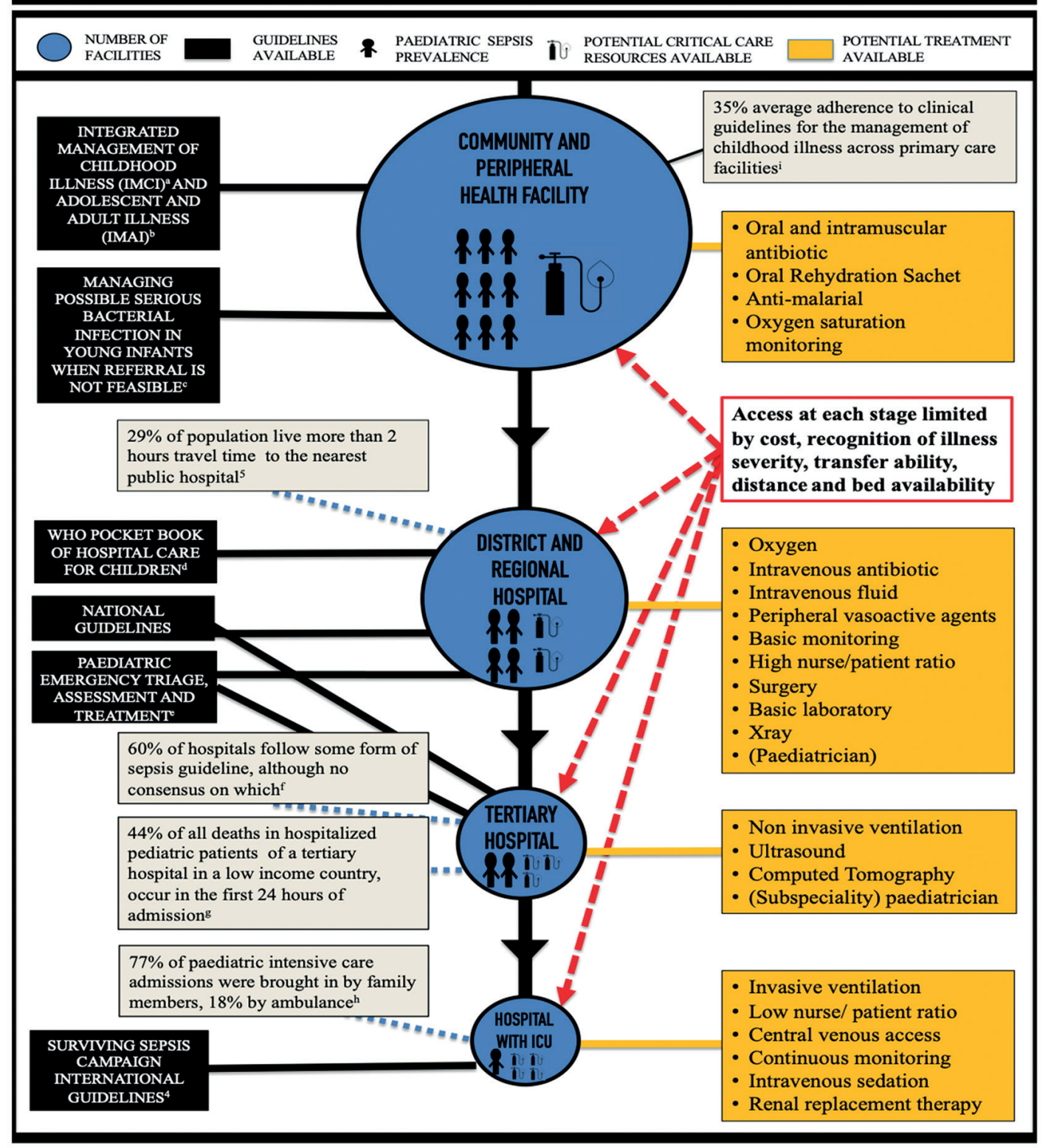

Figure 1. Illustration of crucial steps at different levels of care for pediatrics sepsis.

tored or reassessed ${ }^{9}$. Source control can be challenging (SSG recommendation 15) with significant shortages of surgeons and anaesthetists ${ }^{10}$ and limited diagnostic imaging. Limited microbiologic diagnostics restricts the ability to tailor antimicrobial therapy (SSG recommendations 8,9) and continued use of and an overreliance on broad-spectrum antibiotics (SSG recommendation 7) prompts legitimate concerns of increased antimicrobial resistance and a rise in opportunistic infections. Other high technology resources such as renal replacement therapy and extracorporeal mem- brane oxygenation are limited to a minimal number of PICUs in RLS (SSG recommendations 71,73,74).

\section{Disease Pattern}

In RLS, there is a high sepsis burden of various infectious aetiologies not seen often in resource-rich settings, including measles, malaria, tuberculosis, yellow fever, and dengue. Furthermore, a large proportion of children in RLS have significant comorbidities, including malnutrition, chronic anaemia, and HIV infection. Managing a malnourished child that is critically 


\section{Table 1. Challenges of implementing current surviving sepsis guidelines in resource limited settings}

\begin{tabular}{|c|c|}
\hline SSG recommendations & Potential challenges of SSG implementation in RLS \\
\hline $\begin{array}{l}\text { Screening, diagnosis, and systematic } \\
\text { management of sepsis 1-4 }\end{array}$ & $\begin{array}{l}\text { - No reliable method of clinically diagnosing sepsis, septic shock, and sepsis-associated organ } \\
\text { - Lysfunction, including in the neonatal age group. } \\
\text { - Limited specificity of Systemic Inflammatory Response Syndrome (SIRS) in low- and middle-income } \\
\text { - Heterogeneity in disease pattern and burden of sepsis across resource limited settings (RLS). } \\
\text { - Inconsistent triage in emergency departments. } \\
\text { - Limited validated paediatric mortality prediction models/scoring systems in LMIC to identify the } \\
\text { at-risk child with sepsis. } \\
\text { - Lack of consensus on diagnostic criteria of shock. } \\
\text { - Limited laboratory facilities to diagnose infections, SIRS, Multi-Organ Dysfunction Syndrome } \\
\text { (MODS), measure lactate levels, and evaluate blood cultures. }\end{array}$ \\
\hline Antimicrobial therapy 5-14 & $\begin{array}{l}\text { - The rise in antimicrobial resistance (AMR) and lack of access to effective therapies for AMR } \\
\text { infections. } \\
\text { - Undocumented pre-hospital antibiotic treatment by unqualified or unlicensed practitioners working } \\
\text { in private practice. } \\
\text { - Limited laboratory facilities to tailor antimicrobial therapy leading to overtreatment and AMR. } \\
\text { - Poor supply chain infrastructure for novel antibiotics. } \\
\text { - Widespread use of empiric antibiotics and limited antimicrobial stewardship. } \\
\text { - Numerous areas of endemic disease which can present like sepsis e.g., malaria, dengue. } \\
\text { - Reduced ability to accurately adjust antimicrobial doses for renal and hepatic impairment or } \\
\text { according to drug levels. }\end{array}$ \\
\hline Source control 15-16 & $\begin{array}{l}\text { - Limited surgical and anaesthetic capacity. } \\
\text { - Limited availability of personal protective equipment and infection control measures. }\end{array}$ \\
\hline Fluid therapy $17-23$ & $\begin{array}{l}\text { - Challenges with supply chain (occasionally first line/recommended fluids insufficient or poorly } \\
\text { available). } \\
\text { - Limited ability to mitigate fluid-related complications (fluid overload, capillary leak syndrome, } \\
\text { electrolyte shifts) in the presence of co-existing severe malnutrition }\end{array}$ \\
\hline Haemodynamic monitoring 24-27 & $\begin{array}{l}\text { - Limited hemodynamic monitoring, lactate measurement, and access to additional invasive } \\
\text { monitoring. }\end{array}$ \\
\hline Vasoactive medications $28-33$ & $\begin{array}{l}\text { - Noradrenaline, dopamine, and vasopressin not on WHO Model List of Essential Medicines for } \\
\text { - No guidren. } \\
\text { dilutions to use. } \\
\text { - Limited availability of central venous catheters and providers skilled in central venous access. }\end{array}$ \\
\hline Ventilation 34-43 & $\begin{array}{l}\text { - Limited access to supplemental oxygen and reliable electrical power supply. } \\
\text { - Limited access to continuous oxygen saturation and end-tidal carbon dioxide monitoring. } \\
\text { - Limited guidance on the benefit of non-invasive ventilation in sepsis (especially beyond the neonatal/ } \\
\text { infant age) in RLS. } \\
\text { - Limited access to invasive and non-invasive ventilation equipment. } \\
\text { - Limited critical care training and staff availability. }\end{array}$ \\
\hline Corticosteroids $44-45$ & $\begin{array}{l}\text { - Access to hydrocortisone may be limited despite being on WHO Model List of Essential Medicines } \\
\text { for Children. }\end{array}$ \\
\hline Endocrine and metabolic $46-50$ & - Access to insulin and the ability to regularly monitor blood glucose levels may be limited. \\
\hline Nutrition 51-64 & $\begin{array}{l}\text { - Nasogastric tube feeding is often left to parents to administer due to lack of feeding pumps and } \\
\text { limited nursing availability. } \\
\text { - Limited infrastructure for the elevation of the head of the bed, resulting in flat positioning and an } \\
\text { increased risk for aspiration. } \\
\text { - No recommendation was provided regarding vitamin A supplementation for children with measles/ } \\
\text { malnutrition or zinc for children with acute diarrheal illness. }\end{array}$ \\
\hline Blood products $65-68$ & $\begin{array}{l}\text { - Access to blood products is varied, despite blood being on the WHO Model List of Essential } \\
\text { Medicines for Children. } \\
\text { - Limited capacity to safely administer measured volumes of blood, a frequent cause of overload/ } \\
\text { over-transfusion. } \\
\text { - Transfusion targets poorly defined in RLS. }\end{array}$ \\
\hline $\begin{array}{l}\text { Plasma exchange, renal replacement, } \\
\text { and extracorporeal support } 69-74\end{array}$ & $\begin{array}{l}\text { - Use of renal replacement therapy and extracorporeal membrane oxygenation is limited to a minimal } \\
\text { number of PICUs in LMICs. }\end{array}$ \\
\hline $\begin{array}{l}\text { Immunoglobulins and Prophylaxis } \\
75-77\end{array}$ & $\begin{array}{l}\text { - Under the recommended treatment circumstances, access to ranitidine and omeprazole, as well as } \\
\text { enoxaparin, is variable despite all being on WHO Model List of Essential Medicines for Children. }\end{array}$ \\
\hline
\end{tabular}


ill requires a specific management strategy and is only briefly mentioned in the SSG despite the substantial burden of these conditions (SSG recommendations $7,8,9)$. The duration of illness prior to presentation for care is longer in this setting ${ }^{11}$ due to a lack of illness recognition and issues accessing healthcare, producing a form of "sub-acute sepsis", which is not often seen in resource-rich settings and is not discussed in the guidelines. The aggressive management of true, acute sepsis may not be appropriate for these patients ${ }^{11,12}$, and educating and promoting early identification by parents and healthcare workers is vital. In addition, diarrheal disease is a significant cause of sepsis in RLS ${ }^{1}$, and its unique treatment, including a substantial amount of fluid therapy, electrolyte, and zinc supplementation, is not alluded to in the SSG. Recommendations related to how to evaluate for or intervene upon the high reported mortality upon discharge after sepsis ${ }^{13}$ in RLS are also absent.

\section{Availability of resources}

International and national paediatric sepsis guidelines may not be feasible in rural health facilities with limited availability of essential and frequent costly treatments such as oxygen and intravenous fluids. The utility of low-cost monitoring with devices such as handheld pulse oximeters in a wide range of diseases, including sepsis, needs to be established ${ }^{14}$. Additionally, appropriate interventions (supplemental oxygen, non-invasive ventilation) are not often available even if hypoxia is determined. One study demonstrated that only $44 \%$ of 231 health centres in 12 African countries had access to an oxygen source ${ }^{15}$. Furthermore, clinical signs are often the only indicator of cardiac output and perfusion available to those working in RLS (SSG recommendations 25-27), with no lactate or central venous saturation monitoring access. Haemodynamic monitoring, including a simple sphygmomanometer, and the ability to ventilate (invasively or non-invasively) is sparse (SSG recommendations 3443 ). Access to blood products is variable (SSG recommendations 65-68); it is estimated that $61 \%$ of 195 countries do not have sufficient blood product supply to meet transfusion needs ${ }^{16}$. Further exploration of the safe use of early vasopressors at district-level facilities is required, as is additional work on non-invasive ventilation in RLS.

Sepsis is a syndrome and dynamic in nature. A precise clinical definition is therefore difficult, especially in children. Furthermore, the current definition of sepsis requires the derangement of several clinical agebased parameters and a white cell count ${ }^{17}$. As a result, its use may not be feasible in many health care centres with limited access to laboratory resources and skilled health care workers.

\section{Evidence base}

Of the 506 references in the SSG, only 35 (7\%) were exclusively from data generated in low- and middle-income countries (LMICs), reflecting the fact that either few studies are being undertaken in RLS or are not published on this important topic. Therefore, it is not surprising that recommendations from the SSG may not be truly representative of LMICs populations or experiences of providers in these settings ${ }^{18}$. However, it should be noted that one of the six-strong recommendations made in the SSG is derived from a study conducted in several LMICs ${ }^{12}$. The recommendation advocates for restricting fluid resuscitation and avoiding fluid boluses in settings where intensive care is unavailable and in the absence of hypotension. Overall, attempts were made by the authors of the SSG to include literature from RLS, including several resource-specific recommendations (2 of 77, SSG 18-19). Still, additional information was largely not available for inclusion as the studies have not been done or published. There is an urgent need for more evidence from RLS on feasible, efficacious approaches to the management of sepsis and septic shock that could be included in future guidelines and additional context-specific recommendations (table 2). This is of particular importance as it is increasingly evident that interventions postulated to improve sepsis outcomes in resource-rich settings may not be of benefit and may even cause harm in RLS ${ }^{11,12,19}$.

Global research collaborations to connect researchers from RLS and enhance research capacity, competency building, and promotion of quality improvement initiatives in places with the highest sepsis burden, may be the most efficacious way to approach the paucity of available data. The inclusion of RLS researchers in the entire research process will ensure the needs of the population at study are met ${ }^{20}$.

\section{Context-specific guidelines: a future direction}

The number of children under the age of 5 dying has halved from $1990^{2}$. This is likely a combination of economic development, widespread vaccination programs, improved access to healthcare, sanitation, and clean water, prevention of mother to child HIV transmission and paediatric antiretroviral roll-out, as well as enhanced quality of maternal care. If we are to tackle the huge burden of paediatric sepsis, ongoing implementation of these preventative measures is crucial. However, there will always be a need to manage critically ill children with severe sepsis. As death from sepsis in a large number of cases is preventable, using our status as health care professionals to advocate for the measures mentioned above is essential. Balancing the appropriateness of high-cost, resource-intensive criti- 


\section{Table 2. Recommended areas of future paediatric sepsis research in RLS and SSG adaptations}

\begin{tabular}{|c|c|}
\hline $\begin{array}{l}\text { Paediatric sepsis in RLS: possible areas of future } \\
\text { research }\end{array}$ & Recommendations to consider for future SSG RLS adaptation \\
\hline $\begin{array}{l}\text { Clinical sepsis diagnosis and prevalence in the } \\
\text { community }\end{array}$ & $\begin{array}{l}\text { - More emphasis on clinical signs rather than on laboratory results and how to interpret } \\
\text { the findings } \\
\text { - Dissemination standardised tools for the early detection of sepsis and manage the } \\
\text { implementation of triage areas } \\
\text { - Endorsement of a clinical approach to the septic patient for whom monitoring is not } \\
\text { available } \\
\text { - Guidance on rationing and redirection of treatment, if resources are limited or } \\
\text { treatment is futile }\end{array}$ \\
\hline Fluid therapy in specific disease groups & $\begin{array}{l}\text { - Specific mention and guidance on fluid therapy and treatment of sepsis in the context } \\
\text { of diarrheal disease } \\
\text { - Specific mention and guidance on fluid therapy, transfusion, and treatment of the } \\
\text { malnourished septic child }\end{array}$ \\
\hline $\begin{array}{l}\text { Critical care interventions outside of the PICU, } \\
\text { including critical care training }\end{array}$ & $\begin{array}{l}\text { - Guidance on the use of non-invasive ventilation in areas unable to facilitate intubation } \\
\text { - Clearer guidance on concentration and titration of peripheral inotropes and } \\
\text { - Gasopressors } \\
\text { access to other modes of renal replacement therapy } \\
\text { - The WHO has published specific guidelines that are intended to be contextually } \\
\text { appropriate for managing sepsis in RLS. These published works offer a template to } \\
\text { guide further RLS recommendations in primary care/district level settings or those with } \\
\text { minimal critical care training. }\end{array}$ \\
\hline Antibiotic use & $\begin{array}{l}\text { - Clearer guidance on empiric antibiotic use and when to cease antibiotics if no } \\
\text { inflammatory markers or cultures are available }\end{array}$ \\
\hline Guideline implementation and dissemination & $\begin{array}{l}\text { - Guidelines based on local epidemiology in RLS including typhoid fever, malaria, } \\
\text { dengue, and HIV }\end{array}$ \\
\hline $\begin{array}{l}\text { Work on sepsis education, early identification and } \\
\text { risk prediction }\end{array}$ & $\begin{array}{l}\text { - Validated paediatric mortality prediction models/scoring systems in RLS to identify the } \\
\text { at-risk child with sepsis }\end{array}$ \\
\hline
\end{tabular}

RLS, resource limited settings; SSG, surviving sepsis campaign; WHO, world health organization; HIV, human immunodeficiency virus.

cal care interventions with that of widespread public health interventions should be integral to the global growth of paediatric critical care ${ }^{21}$.

The provision of critical care in sepsis need not require a highly resourced intensive care unit. It can be as simple as the timely delivery of appropriate antibiotics and close monitoring by trained healthcare professionals. With limited critical care capacity and training, enabling healthcare professionals working in RLS to deliver simple critical care at every patient's bedside, regardless of location and resource availability, should be our ambition. Development and implementation of context and resource-specific emergency and critical care education and training for all those involved in paediatric sepsis care in RLS will help achieve this goal $^{22}$. Context-specific guidelines, built on a foundation of high-quality research and crafted to facilitate the management of the critically ill child in different health care settings ${ }^{23}$ by a range of professionals with simple and ubiquitous low-cost technology, could be one component of a minimum standard of paediatric sepsis critical care. Therefore, it is incumbent on us to ensure any guidance produced reaches and is meaningful to those most in need, fully inclusive of both health care professionals and literature from RLS. Although several authors may have clinical or academic ties to RLS, only two authors (3.5\%) of the SSG were affiliated to an institution in LMICs, and a further $2(3.5 \%)$ to an institution in an upper-middle-income country. Promoting diversity in authorship ${ }^{24}$, and fair representation of healthcare professionals from RLS that are managing the vast majority of children with sepsis in the world may mitigate against generalizing guidelines designed in resource-rich countries for use globally.

Despite many barriers, previous work has shown that it is feasible to implement modified sepsis guidelines that are scaled to resource availability ${ }^{25}$. The importance of implementing a local protocol for managing children with septic shock or other sepsis-associated organ dysfunction (SSG recommendation 3) 
is discussed in the SSG. Still, it needs to be modified to recommend tiered guidelines that are applicable and empowering to both the health worker in a remote clinic and the paediatrician in a tertiary centre. The central involvement of those healthcare workers who currently deal with the vast burden of sepsis in RLS is paramount. There is a clear demand for ethical guidance over the prioritization of resources and costeffectiveness of interventions to those most critically ill. The ongoing development of research capacity in RLS to better inform future guidelines is also crucial. Despite resource constraints and the heterogeneity and diversity of scenarios in RLS, researchers in these regions have been conducting high-quality randomized controlled trials and changing paradigms in the process. Highlighting these efforts and building upon those networks is integral to future sepsis research, and their expansion to larger multi-centre trials should be actively encouraged. With a child's high potential for recovery, the SSG has an important role to play in re- ducing mortality and morbidity from this devastating disease at all levels of care in RLS.

\section{Conclusion}

The needs and resources of those working in a RLS differ substantially from those in resource-rich settings. Therefore, the various challenges faced when considering the implementation of the SSG in RLS need to be taken into consideration during future international paediatric sepsis and septic shock guideline development. The guidelines, however, successfully draw attention to the frequently under-recognized problem of paediatric sepsis and highlight the current lack of highquality evidence related to the subject. Based on this review, we believe there is an urgent need for more evidence from RLS to aid the development of a more globally applicable, context-specific set of guidelines for use in RLS, where most sepsis cases and deaths occur.

\section{References}

1. Rudd KE, Johnson SC, Agesa KM, et al. Global, regional, and national sepsis incidence and mortality, 1990-2017: analysis for the Global Burden of Disease Study. Lancet. 2020;395(10219):200-11.

2. United Nations Inter-Agency Group for Child Mortality Estimation (UN IGME), 'Levels \& Trends in Child Mortality: Report 2020, Estimates developed by the United Nations Inter-agency Group for Child Mortality Estimation', United Nations Children's Fund, New York 2020

3. Weiss SL, Fitzgerald JC, Pappachan J, et al. Global epidemiology of paediatric severe sepsis: the sepsis prevalence, outcomes, and therapies study [published correction appears in Am J Respir Crit Care Med. 2016 Jan 15;193(2):2234]. Am J Respir Crit Care Med. 2015;191(10):1147-57.

4. Weiss SL, Peters MJ, Alhazzani W, et al. Surviving Sepsis Campaign International Guidelines for the Management of Septic Shock and Sepsis-Associated Organ Dysfunction in Children. Pediatr Crit Care Med. 2020;21(2):e52-e106.

5. Ouma PO, Maina J, Thuranira PN, et al. Access to emergency hospital care provided by the public sector in subSaharan Africa in 2015: a geocoded inventory and spatial analysis. Lancet Glob Health. 2018;6(3):e342-e350.

6. Global health workforce alliance, WHO. A universal truth: no health without a workforce, 2013. P104.
7. Baral B, Prajapati R, Karki KB, et al. Distribution and Skill Mix of Health Workforce in Nepal. J Nepal Health Res Counc. 2013;24:126-32.

8. Ogero M, Ayieko P, Makone B, et al. An observational study of monitoring of vital signs in children admitted to Kenyan hospitals: an insight into the quality of nursing care? J Glob Health. 2018;8(1):010409.

9. Nolan T, Angos P, Cunha AJ, et al. quality of hospital care for seriously ill children in less-developed countries. Lancet Lond Engl. 2001;357:106-10.

10. Holmer H, Lantz A, Kunjumen T, et al. Global distribution of surgeons, anaesthesiologists, and obstetricians. Lancet Glob Health. 2015;3 Suppl 2:S9S11.

11. Andrews B, Semler MW, Muchemwa L, et al. Effect of an Early Resuscitation Protocol on In-hospital Mortality Among Adults With Sepsis and Hypotension: A Randomized Clinical Trial. JAMA. 2017;318(13):1233-40.

12. Maitland K, Kiguli S, Opoka RO, et al; FEAST Trial Group. Mortality after fluid bolus in African children with severe infection. N Engl J Med. 2011; 364(26):2483-95.

13. Wiens MO, Kumbakumba E, Kissoon N, et al. Paediatric sepsis in the developing world: challenges in defining sepsis and issues in post-discharge mortality. Clin Epidemiol. 2012;4:319-25.

14. King C, Boyd N, Walker I, et al. Opportunities and barriers in paediatric pulse oximetry for pneumonia in low- resource clinical settings: a qualitative evaluation from Malawi and Bangladesh. BMJ Open. 2018;8(1):e019177.

15. Belle J, Cohen H, Shindo N, et al. Influenza preparedness in low-resource settings: a look at oxygen delivery in 12 African countries. J Infect Dev Ctries. 2010;4(7):419-24.

16. Roberts N, James S, Delaney M, et al. The global need and availability of blood products: a modelling study. Lancet Haematol. 2019;6(12):e606-e615.

17. Goldstein B, Giroir B, Randolph A. International Consensus Conference on Pediatric Sepsis. International pediatric sepsis consensus conference: definitions for sepsis and organ dysfunction in pediatrics. Pediatr Crit Care Med. 2005;6(1):2-8.

18. Keating EM, Haq H, Rees CA, et al. Global Disparities Between Paediatric Publications and Disease Burden From 2006 to 2015. Glob Pediatr Health. 2019; 6:2333794X19831298.

19. Kortz TB, Axelrod DM, Chisti MJ, et al. Clinical outcomes and mortality before and after implementation of a paediatric sepsis protocol in a limited resource setting: A retrospective cohort study in Bangladesh. PLoS One. 2017;12(7):e0181160.

20. Belizán JM, Miller S. What can WHO do to support research in LMICs? Lancet. 2017; 389(10080):1697.

21. Murthy S, Chugh K, Musa N, et al. Editorial: Paediatric Critical Care in Resource-Limited Settings. Front Pediatr. 2019;7:80. 
22. Schell CO, Gerdin Wärnberg M, Hvarfner A, et al. The global need for essential emergency and critical care. Crit Care. 2018;22(1):284.

23. WHO (2015) Guideline: Managing possible serious bacterial infection in young infants when referral is not feasible. https://www.who.int/maternal_ child_adolescent/documents/bacterialinfection-infants/en/. Accessed 17/9/20.

24. Hetzel MW, Bonfoh B. Towards more balanced representation in Lancet Commissions. Lancet. 2020; 395(10238):1693-4.

25. Mahavanakul W, Nickerson EK, Srisomang P, et al. Feasibility of modified surviving sepsis campaign guidelines in a resource-restricted setting based on a cohort study of severe $S$. aureus sepsis [corrected] [published correction appears in PLoS One. 2012;7(5): doi/10.1371/annotation/7f498e31-270944f6-877a-d0ee89bebe03]. PLoS One. 2012;7(2):e29858. 